Pesq. Vet. Bras. 36(7):605-610, julho 2016 DOI: $10.1590 / \mathrm{S} 0100-736 \mathrm{X} 2016000700008$

\title{
Detecção e tratamento de otite por Rhabditis blumi em bovinos da região Norte do Brasil ${ }^{1}$
}

\author{
José Diomedes Barbosa ${ }^{2 *}$, Jenevaldo Barbosa da Silva ${ }^{3}$, Danillo Henrique da Silva \\ Lima $^{2}$, Luiz Henrique Vilela Araújo ${ }^{2}$, Lívia Loiola dos Santos ${ }^{2}$, Alessandra dos S. \\ Belo Reis ${ }^{2}$, Felipe Masiero Salvarani ${ }^{2}$ e Marilene de Farias Brito ${ }^{3}$
}

\begin{abstract}
Barbosa J.D., Silva J.B., Lima D.H.S., Araújo L.H.V., Santos L.L., Belo Reis A.S., Salvarani F.M. \& Brito M.F. 2016. [Detection and treatment of otitis by Rhabditis blumi in cattle of northern Brazil.] Detecção e tratamento de otite por Rhabditis blumi em bovinos da região Norte do Brasil. Pesquisa Veterinária Brasileira 36(7):605-610. Instituto de Medicina Veterinária, Campus de Castanhal, Universidade Federal do Pará, Rodovia BR-316 Km 61, Castanhal, PA 68741-740, Brazil. E-mail: diomedes@ufpa.com

This study aimed to describe the occurrence of parasitic otitis caused by Rhabditis blu$m i$ in dairy cattle of the Gir race from a farm in northern Brazil. Forty-two samples were collected from cattle by swab washed from the external auditory canal (EAC). On clinical examination, in $71.4 \%(30 / 42)$ of the cattle the parasite was found in the cerumen of the ear canal, along with alopecia of head and hump caused by discomfort and itching of the auricular region. At microscopic analysis of material from the conjunctival sac the parasite was found in $90 \%(9 / 10)$ of the evaluated cattle. In addition, 9.5\% (4/42) of the cattle showed nervous symptoms, such as mild to moderate rotation of the head, apathy, flaccid lips and unilateral ptosis, change in chewing and food accumulation in the oral cavity. Thirty cattle positive for Rhabditis spp. were randomly divided into three groups of 10 animals each: (G1) Cattle Control, (G2) Cattle treated with ivermectin 1\% pour-on, and (G3) Cattle undergoing wash of the external auditory canal (EAC). Each treatment was repeated three times with intervals of seven days. In G1, 10 cattle remained infected throughout the study. In G2, 20\% of the cattle were negative after the first two treatments, however were positive at the third evaluation. In G3, all cattle remained positive, but with decrease in parasite load. Identification by molecular analysis of amplified fragments through the expansion D2/D3 28S rDNA confirmed the presence of only Rhabditis blumi. Based on clinical, morphologic and molecular examination, it appears to be the first report of the occurrence of $R$. blumi infection in Gir cattle in the State of Pará, due to the purchase of cattle from areas where parasitic otitis has been diagnosed, as from Minas Gerais, to produce crossbred animals (Gir x Holstein). This emphasizes the importance of prior clinical examination by the veterinary service in order to transfer only healthy animals to other properties or regions. This appears also to be the first report on R. blumi infection of the conjunctival sac in cattle. Treatment with ivermectin in G2 did not produce clinical improvement.
\end{abstract}

INDEX TERMS: Brazil, cattle, 28S gene, ivermectin, Rhabditis blumi, conjunctival gland.

\footnotetext{
${ }^{1}$ Recebido em 30 de maio de 2015.

Aceito para publicação em 3 de junho de 2016.

${ }^{2}$ Faculdade de Medicina Veterinária, Instituto de Medicina Veterinária, Campus de Castanhal, Universidade Federal do Pará (UFPA), Rodovia BR316 Km 61, Castanhal, PA 68741-740, Brasil. *Autor para correspondência: diomedes@ufpa.br

${ }^{3}$ Departamento de Epidemiologia e Saúde Pública, Instituto de Veterinária, Universidade Federal Rural do Rio de Janeiro (UFRRJ), Seropédica, RJ 23890-000, Brasil.
}

RESUMO.- 0 presente estudo teve como objetivo descrever a ocorrência de otite parasitária causada por Rhabditis blumi em bovinos leiteiros de raça Gir de uma fazenda da região Norte do Brasil. Foram coletadas amostras de 42 bovinos por swab e lavado dos condutos auditivos externos (CAE). Ao exame clínico, 9,5\% (4/42) dos bovinos apresentavam sintomatologia nervosa, como leve a moderada rotação da cabeça, apatia, flacidez dos lábios e ptose palpebral 
unilateral, alopecia das regiões da cabeça e cupim, causados pelo desconforto e prurido da região auricular, alteração na mastigação e acúmulo de alimento na cavidade oral. Adicionalmente, 71,4\% (30/42) dos abovinos mostraram a presença do parasita no cerúmen dos condutos auditivos. À análise microscópica do material do saco conjuntival foi observado presença do parasita em 90\% (9/10) dos bovinos avaliados. Os 30 bovinos positivos para Rhabditis spp. foram distribuídos aleatoriamente em três grupos de 10 animais: (G1) Bovinos controle, (G2) Bovinos tratados com ivermectina $1 \%$ pour on e (G3) Bovinos submetidos a lavado dos condutos auditivos externos (CAE). Cada tratamento foi repetido três vezes com intervalo de sete dias. No G1 os 10 bovinos mantiveram-se infectados durante todo o estudo. No G2 20\% dos bovinos foram negativos após os dois primeiros tratamentos, porém, mostraram-se positivos na terceira avaliação. No G3 todos os bovinos mantiveram-se positivos, sendo observada apenas diminuição da carga parasitária. A identificação por análise molecular por meio de fragmentos amplificados da expansão D2/D3 do 28S rDNA confirmou a presença apenas da espécie Rhabditis blumi nos animais. Baseado nas observações clínicas, morfológicas e moleculares pode-se relatar o primeiro caso de $R$. blumi em bovinos da raça Gir no Estado do Pará, através da compra de animais oriundos de áreas onde a otite parasitária tem sido diagnosticada, principalmente de Minas Gerais, para formar animais mestiços (Gir x Holandês). Desta forma ressalta-se a importância do exame clínico prévio dos animais a serem transferidos para outras propriedades ou regiões. Este relato também parece ser o primeiro sobre a presença de R. blumi no saco conjuntival de bovinos. 0 tratamento com ivermectina no G2 não surtiu melhora clínica dos bovinos.

TERMOS DE INDEXAÇÃO: Brasil, bovinos, gene 28S, Ivermectina, Rhabditis blumi, saco conjuntival.

\section{INTRODUÇÃo}

A otite parasitária tem sido diagnosticada na região $\mathrm{Su}$ deste do Brasil, nos estados do Rio de Janeiro (Verocai et al. 2007, Abdalla et al. 2008), de Minas Gerais (Leite et al. 1993, 2010, 2012, 2013, Duarte et al. 2001, Duarte \& Hamdan 2004), de São Paulo (Leite et al. 2012); na região Centro-Oeste, no Estado de Goiás (Vieira et al. 1998, 2001, Campos et al. 2009, Rezende 2010) e na região Nordeste, no estado da Bahia (Leite et al. 2012). Os principais transtornos causados por esta parasitose são decorrentes do incômodo aos animais os quais deixam de se alimentar. Como consequência ocorrem perdas de produção, diminuição do rendimento de carcaça, diminuição na produção de leite, gastos com medicamentos, que às vezes são ineficazes, e até perdas de animais, dentre outros prejuízos que passam despercebidos pelo proprietário (Vieira et al. 2001, Pitombo 2008, Leite \& Leite 2010).

Dentre os agentes etiológicos responsáveis pelas otites em bovinos se destacam os nematoides do gênero Rhabditis. Nesse gênero são encontrados em cinco espécies $R$. freitasi, $R$. costai, R. insectivora, $R$. terrestres e $R$. blumi, e as raças Gir, Indubrasil e seus mestiços, são as mais susceptí- veis (Leite et al. 1993, Bossi et al. 2015). Os sinais clínicos observados são diversos; na otite externa observa-se apenas apatia e balançar da cabeça. Nos casos de otites médias, ambos os ouvidos estão acometidos e há otorreia de odor fétido e coloração castanha escura. Em alguns animais, há presença de muitos parasitas e torna-se possível sua visualização a olho nu. Os bovinos podem ficar apáticos, demonstrar desconforto, balançar de cabeça e tendem a coçar as orelhas com as patas, nas instalações ou em outros animais. Nas otites internas, os sinais clínicos são semelhantes aos da otite média, acrescentados de sintomatologia nervosa devido à evolução para uma síndrome vestibular, caracterizada por nítido rotacionar da cabeça, apatia mais evidente, incoordenação, salivação, problemas de mastigação e acúmulo de alimento na cavidade oral (Msolla et al. 1993, Verocai et al. 2007, Abdalla et al. 2008, Campos et al. 2009, Leite et al. 2010, Rezende 2010).

No Brasil alguns tratamentos para Rhabditis spp. já foram descritos por Leite et al. (1994) e Vieira et al. (2001), com resultados variáveis. Leite et al. (1994) indicaram como tratamento eficaz a lavagem do conduto auditivo dos animais com uma solução de álcool e éter na proporção 1:1, contendo sulfato de cobre a $2 \%$. No entanto, Vieira et al. (2001) compararam o tratamento anteriormente descrito com uma solução de triclorfon a $3 \%$ e dimetilsulfóxido a $1 \%$, utilizando como veículo uma pasta de nitrofurazona, e não obtiveram o efeito terapêutico desejado em ambos os grupos.

O objetivo do presente estudo foi relatar a ocorrência de otite parasitária causada por Rhabditis blumi em face da compra de bovinos oriundos de áreas onde a otite parasitária tem sido diagnosticada, principalmente de Minas Gerais, para formar mestiços Gir x Holandês e a ocorrência desse nematoide no saco conjuntival em vacas da raça Gir no estado do Pará, Brasil. Adicionalmente, foi avaliado o uso de lavagem do conduto auditivo e o uso de ivermectina no tratamento contra R. blumi.

\section{MATERIAL E MÉTODOS}

Amostras. 0 estudo foi realizado em uma propriedade de pecuária leiteira localizada no município de Santa Isabel do Pará (latitude $01^{\circ} 17^{\prime} 55^{\prime \prime}$ Sul e longitude $48^{\circ} 09^{\prime} 38^{\prime \prime}$ Oeste), estado do Pará, região Norte do Brasil. A propriedade possuía um plantel de 300 bovinos, sendo 90 da raça Gir (Bos indicus) e 210 mestiços (Gir x Holandês). Para a coleta de dados e realização de exames clínicos dos animais realizou-se visitas técnicas à propriedade entre maio e junho de 2014.

Para as coletas, os animais foram contidos em tronco com imobilização da cabeça com o uso de cordas. Foram selecionadas aleatoriamente 42 das 90 fêmeas da raça Gir. Foram coletadas amostras dos 42 animais pela técnica do swab. Adicionalmente, 30 destes animais também foram avaliados simultaneamente pela técnica de lavado do conduto auditivo externo (CAE) (Fig.1). As técnicas utilizadas foram baseadas em Leite et al. (1989) e Leite et al. (1994) com modificações. Para a técnica do lavado do CAE foi utilizada uma seringa de $20 \mathrm{ml}$ acoplada a um equipo de $30 \mathrm{~cm}$ para lavagem do conduto auditivo externo dos bovinos, onde foi coletado o material em uma bandeja inox. As amostras foram acondicionadas em tubos tipo Falcon para posterior identificação do parasita. 


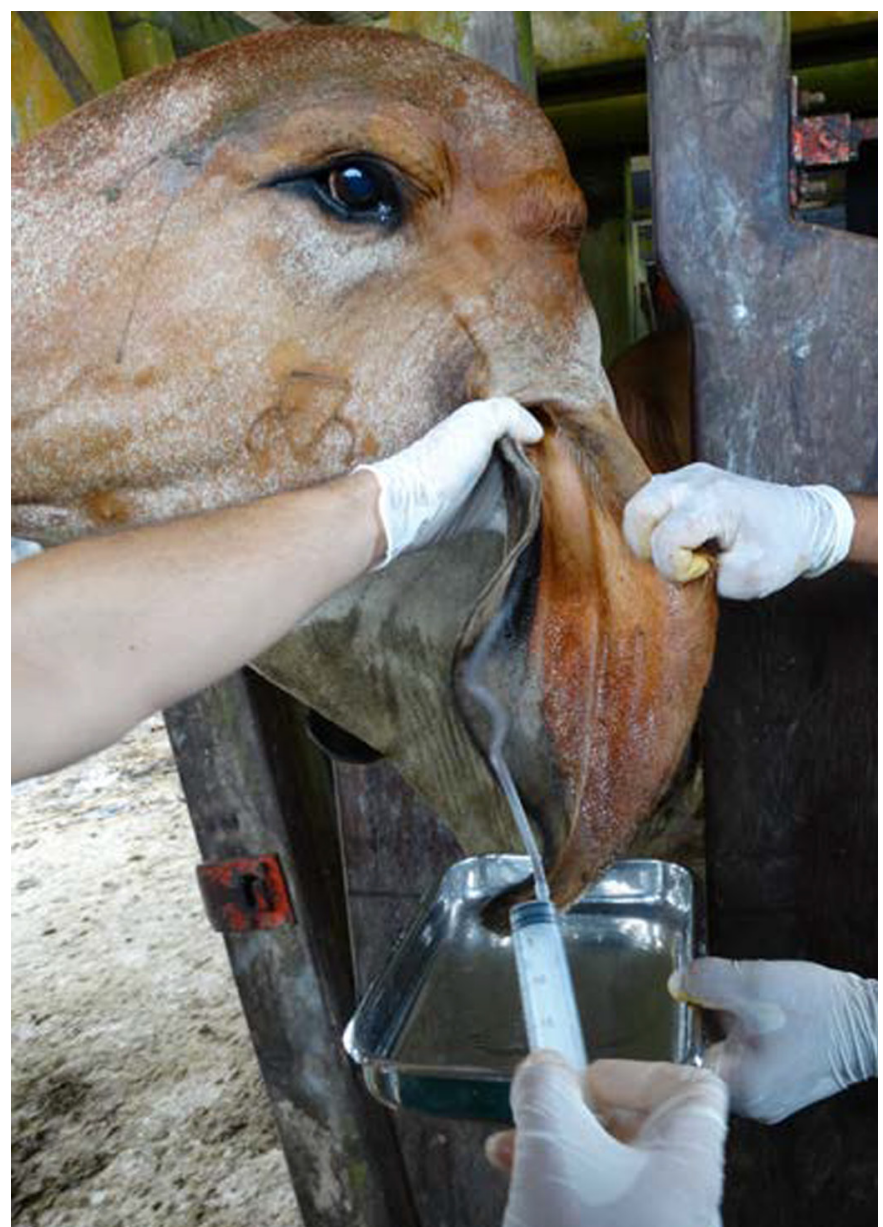

Fig.1. Coleta de material através de lavado do conduto auditivo externo em bovino da raça Gir com otite.

O material coletado com swab e lavado foram avaliados macroscópica e microscopicamente. Para o exame microscópico foram adicionados $5 \mathrm{ml}$ de solução fisiológica ao material coletado com swab. Essas amostras e as provenientes do lavado foram centrifugadas em centrífuga modelo LS 3 PLUS-CELM por $10 \mathrm{mi}-$ nutos. Após esse procedimento, o sobrenadante foi descartado e uma gota do sedimento foi colocada em uma lâmina de microscopia, acrescida de uma gota de lugol, coberta por uma lamínula para posterior visualização em microscópio modelo ECLIPSE E200. Adicionalmente, foi coletado material do saco conjuntival de 10 animais, com o uso de swab para pesquisa do parasita. Após a coleta, as amostras foram processadas de acordo com os procedimentos adotados para as amostras coletadas por swab do pavilhão auricular (Leite et al. 1994). 0 exame clínico geral e específico do sistema nervoso foi realizado de acordo com Dirksen et al. (1993).

Ainda foram realizados raspados de pele das regiões alopécicas da cabeça e cupim para observação em microscopia óptica.

Identificação molecular de Rhabditis spp. O DNA genômico foi extraído dos parasitos mantidos em placas de Petri com ágar sangue e foram separados individualmente em tubos com solução de Tris-EDTA. As espécimes foram incubadas com tampão de digestão (Tris $\mathrm{HCl} 10 \mathrm{mM}$, EDTA 0,5M, NaCl 5M, SDS 2\% e DTT $0,65 \mathrm{M}$ ) e proteinase $\mathrm{K}$ overnight, seguida de extração com fenol:clorofórmio:álcool isoamílico (Sambrook et al. 1989). 0 DNA foi precipitado com acetato de sódio 3M e etanol $100 \%$. 0 pellet foi, então, lavado com etanol 70\% e ressuspendido em tampão Tris-EDTA. As amostras foram incubadas overnight a $-4^{\circ} \mathrm{C}$ e, em seguida, a $56^{\circ} \mathrm{C}$ por 30 minutos.
Fragmentos da expansão D2/D3 do 28S rDNA foram amplificados utilizando-se os primers D2F (5'-ACAAGTACCGTGAGGGAAAGTTG-3') e D2R (5'-TCGGAGGGA ACCAGCTACTA-3') (adaptado de Tomazini et al. 2013). A PCR de volume total de $25 \mu \mathrm{L}$ foi realizada utilizando-se 10,5 $\mu \mathrm{L}$ de água ultrapura, 6,5 $\mathrm{L}$ de tampão $5 x$ Colorless Go Taq Flexi (Promega, USA), 2,5 $\mu \mathrm{L}$ de $\mathrm{MgCl} 225 \mathrm{mM}$ (Promega, USA), 0,25 $\mu \mathrm{L}$ de cada primer $(10 \mu \mathrm{M}), 2,5 \mu \mathrm{L}$ de cada dNTP (1mM), 0,25 $\mu \mathrm{L}$ de DNA Polimerase GoTaq Hot Start (Promega) $(5 \mathrm{U} / \mu \mathrm{L})$ e $2,5 \mu \mathrm{L}$ de DNA molde $(50-100 \mathrm{ng} / \mu \mathrm{L})$. As condições da PCR no termociclador automático (Veriti-Life Technologies, USA) foram as seguintes: desnaturação inicial a $95^{\circ} \mathrm{C}$ por $7 \mathrm{~min}$, seguida de 35 ciclos de desnaturação a $94^{\circ} \mathrm{C}$ por $60 \mathrm{~s}$, anelamento a $55^{\circ} \mathrm{C}$ por $60 \mathrm{~s}$ e extensão a $72^{\circ} \mathrm{C}$ por $60 \mathrm{~s}$, com uma etapa final de alongamento a $72^{\circ} \mathrm{C}$ por $10 \mathrm{~min}$ (Mráèek et al. 2006).

Os produtos de PCR $(5 \mu \mathrm{L})$ visualizados em géis de agarose foram selecionados para o sequenciamento. As sequências foram determinadas bi-direcionalmente utilizando-se o kit Big Dye Terminator v.3.1 Cycle Sequencing no sequenciador automático de DNA ABI 3130 (ambos de Life Technologies, USA), de acordo com as instruções do fabricante. As sequências senso e anti-senso foram alinhadas e editadas usando-se o software SeqScape (Life Technologies). Posteriormente as sequências foram alinhadas e comparadas utilizando o software MEGA5 (Tamura et al. 2011). Foram realizadas buscas no GenBank para se identificar a similaridade das sequências depositadas no site do National Center for Biotechnology Information utilizando-se o servidor de rede BLAST.

Tratamento. Para a avalição da eficácia do tratamento foram utilizados 30 bovinos positivos distribuídos aleatoriamente em três grupos:

Grupo 1 (G1): 10 bovinos que não receberam tratamento (controles);

Grupo 2 (G2): 10 bovinos que receberam três aplicações de 5,0mL de pour on à base de Ivermectina $1 \%$ (Ivermectin, $1 \mathrm{mg} / \mathrm{kg}$, Merial, Brazil), via tópica no pavilhão auricular;

Grupo 3 (G3): 10 bovinos que receberam lavagem dos CAE com uma solução de éter e álcool na proporção de 1:1 e sulfato de cobre a $2 \%$.

Foram realizados três tratamentos com intervalos de sete dias em cada um dos grupos. Antes de iniciar o tratamento seguinte, em cada um dos grupos realizou-se a coleta do material do conteúdo auditivo de ambos os lados, para a análise macroscópica e microscópica quanto à presença do nematódeo.

\section{RESULTADOS E DISCUSSÃO}

Em visita realizada à propriedade foi relatado pelo criador que há pelo menos 10 anos, bovinos da raça Gir apresentavam a cabeça torta e lacrimejamento. Foi mencionado ainda que esses animais apresentavam baixo escore corporal, intervalo longo entre partos e que durante esse período havia ocorrido a morte de pelo menos três bovinos com esta sintomatologia. Os animais da raça Gir eram oriundos da compra de bovinos de outros estados, principalmente de Minas Gerais, para formar animais mestiços (Gir x Holandês), usados para formação de planteis para a produção leiteira. Para Abdalla et al. (2008) a compra de animais de outras propriedades do mesmo ou de outros estados é uma das causas de introdução do nematoide no rebanho. Desta forma, provavelmente a compra de animais da raça Gir oriundos de outros estados pode ter contribuído para o alto índice de animais parasitados. 
Nos bovinos mestiços criados junto com os da raça Gir não foi observado aumento do cerúmen nos condutos auditivos externos (CAE), nem animais com sinais clínicos, ao contrário do que foi observado nos bovinos da raça Gir. De acordo com Leite et al. (1993), Duarte et al. (2001), Vieira et al. (2001), Pitombo (2008) e Abdalla et al. (2008) a predileção do parasito rhabditiforme pela raça Gir deve-se à conformação anatômica do pavilhão auricular, que é mais longo e canulado, além de que suas orelhas são pendentes e em forma de calha, o que proporciona um ambiente com calor e umidade favorável para o aumento das secreções, e desenvolvimento e reprodução do nematódeo. Essa conformação anatômica também favorece a retenção do cerume, que associada à presença de pelos, há a proliferação da saprobiose. Duarte et al. (2001) descreveram uma maior ocorrência desta parasitose em bovinos adultos com chifres, o que difere do presente estudo, onde foram observados casos de otite tanto em bovinos com e sem chifres.

Ao exame clínico os bovinos apresentavam aumento do cerúmen do pavilhão auricular com formação de crostas (Fig.2). À inspeção do pavilhão auricular evidenciou-se que $61,9 \%$ (26/42) dos animais apresentavam aumento de cerúmen de coloração cinza claro até marrom claro, o que de acordo com Abdalla et al. (2008), Campos et al. (2009) e Rezende (2010) esse é um achado comum e característico da presença de Rhabditis blumi. Nos 61,9\% dos bovinos com aumento de cerume foi possível verificar a presença, a olho nu, de Rhabditis blumi, ora no CAE ora na parede do tubo Falcon, onde era colocado o swab com o material coletado proveniente do conduto auditivo. De acordo com Leite et al. (1993), Verocai et al. (2007), Vieira (1998), Duarte et al. (2001) e Campos et al. (2009), o diagnóstico da otite causada por helmintos do gênero Rhabditis pode ser realizado pela simples observação, a olho nu, do material coletado por lavagem ou contato direto de um chumaço de algodão hidrófilo com o conduto auditivo.

Ao exame microscópico das amostras coletadas do pavilhão auricular, 30/42 (71,4\%) foram positivas (Fig.3), valor superior à observação realizada a olho nu de 61,9\% (26/42). De acordo com (Leite et al. 1994) a não visualização dos parasitas a olho nu em alguns bovinos pode ser explicado por se tratar de uma otite subclínica com presença de poucos parasitas. No presente estudo, o maior número de bovinos identificados com a presença do parasita no CAE, ao exame microscópico, pode ser explicado pela maior eficiência deste exame, principalmente naqueles animais com baixa carga parasitária, quando comparado com o exame macroscópico.

Duarte et al. (2001) e Duarte \& Hamdan (2004) apontam como diagnóstico diferencial único de otite por Rhabditis um ácaro do gênero Raillietia, cuja as características físicas do material encontrado nessas otites são totalmente diferentes.

A identificação molecular da espécie utilizando-se fragmentos amplificados da expansão D2/D3 do 28S rDNA confirmou a presença apenas da espécie Rhabditis blumi nos bovinos, o que difere de outros relatos da literatura, que descrevem a presença de Rhabditis freitasi, $R$. costai, $R$. insectivora e $R$. terrestres (Martins Jr 1985), atualmente foi identificada a espécie Metarhabditis blumi em casos de otite bovina no estado de Minas Gerais (Bossi et al. 2015). Este estudo descreve pela primeira vez a associação da otite parasitária causada por Rhabditis blumi em bovinos da raça Gir, e o primeiro relato da presença deste parasita no saco conjuntival.

No presente relato os bovinos apresentavam leve a intenso lacrimejamento uni ou bilateral (Fig.4). Ao exame microscópico do material coletado do saco conjuntival foi diagnosticada a presença do parasita em 90\% (9/10) dos bovinos. Rezende (2010) demonstraram uma correlação forte entre o lacrimejamento e os casos de otites. Esses autores mencionaram ainda que, quanto maior a presença do corrimento ocular maior era a presença do parasito nos condutos auditivos externos (CAE), e sem exceção, todos os bovinos que apresentavam o corrimento ocular uni ou bi-

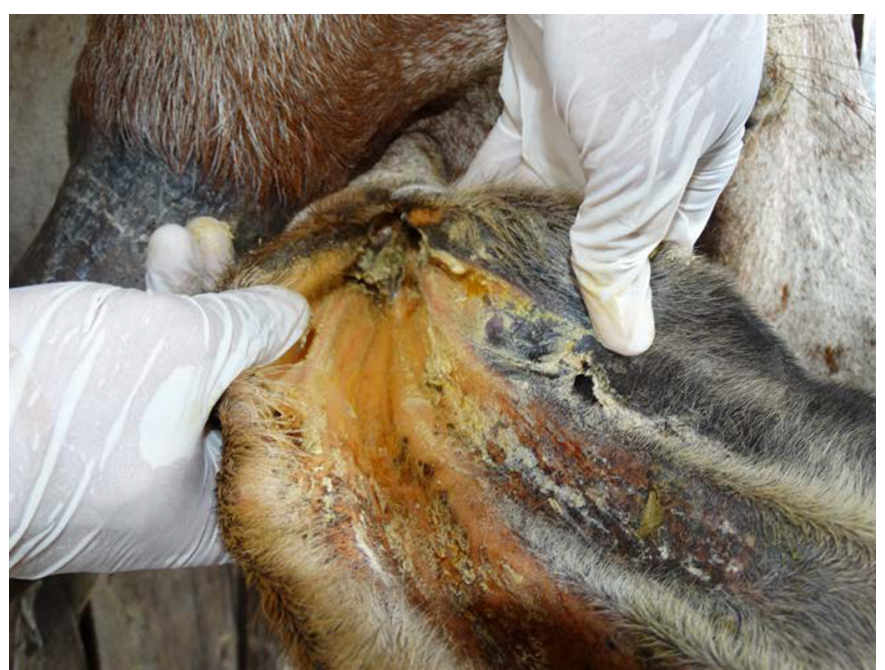

Fig.2. Pavilhão auricular de bovino da raça Gir com aumento de cerúmen e crostas devido ao parasitismo por larvas de Rhabditis blumi.

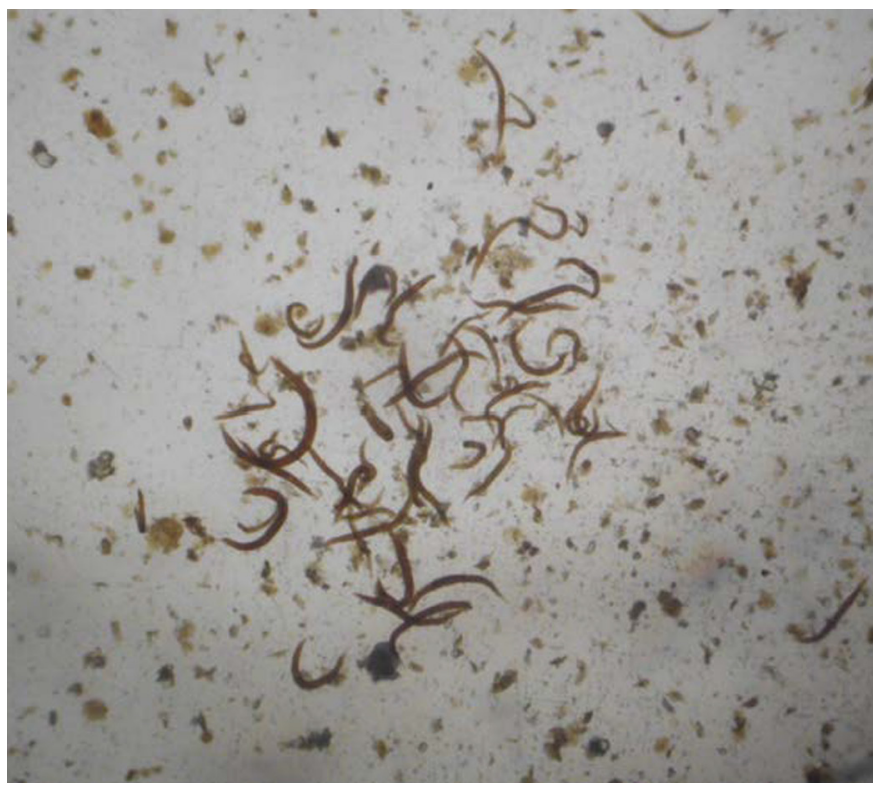

Fig.3. Espécimes de Rhabditis blumi coletados do pavilhão auricular de bovino da raça Gir e analisadas entre lâmina e lamínula em microscopia óptica. Obj.4x. 
lateral também apresentavam a otite uni ou bilateral e vice e versa. O lacrimejamento apresentado pelos bovinos do presente estudo pode ser explicado pela ação irritativa das lavas de R. blumi (Fig.5) encontradas no saco conjuntival, o que está de acordo com a hipótese levantada por Campos et al. (2009). Com relação à forma de transmissão foi aventada a possibilidade da migração das larvas presentes do cerume da região periauricular para o olho (Msolla et al. 1993, Verocai et al. 2007, Abdalla et al. 2008, Campos et al. 2009). Não descartamos o papel das moscas no transporte das larvas do parasita para o globo ocular, como também já foi mencionado por Msolla et al. (1986). Porém, não podemos confirmar hipóteses da forma de transmissão.

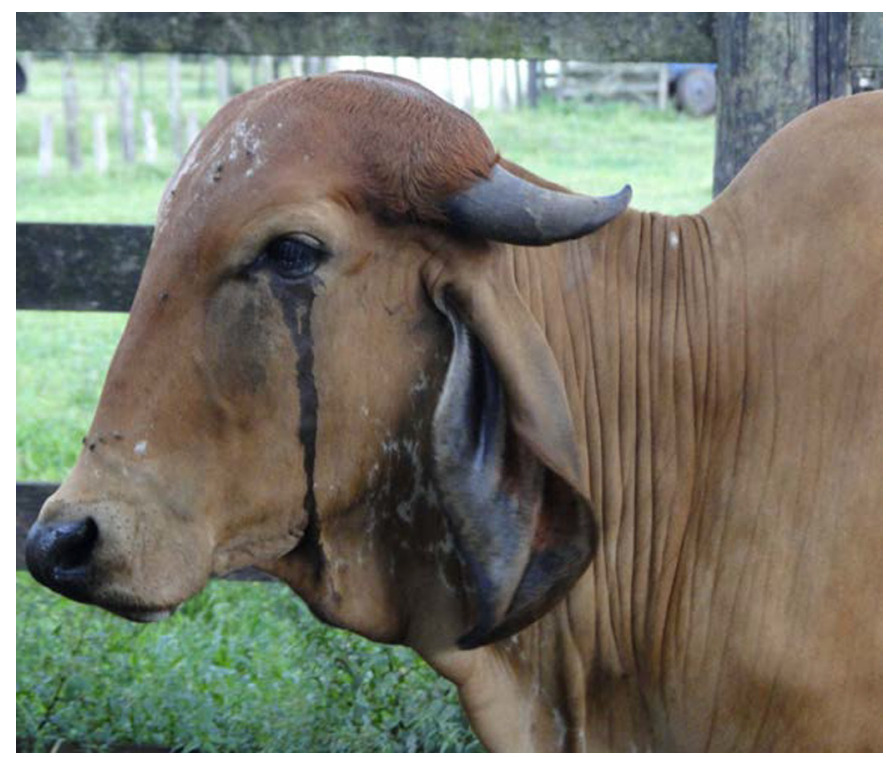

Fig.4. Bovino da raça Gir com lacrimejamento unilateral acentuado, causado por larvas de Rhabditis blumi no saco conjuntival.

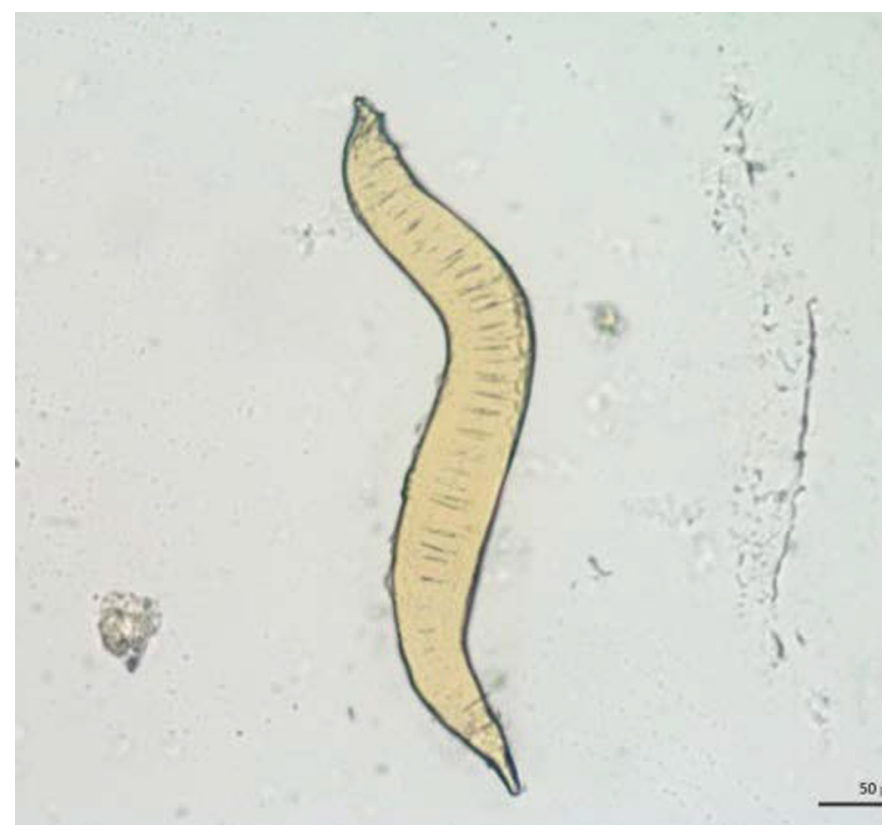

Fig.5. Espécime de Rhabditis blumi coletado do saco conjuntival de bovino da raça Gir com otite e analisada entre lâmina e lamínula em microscopia óptica. Obj.20x.

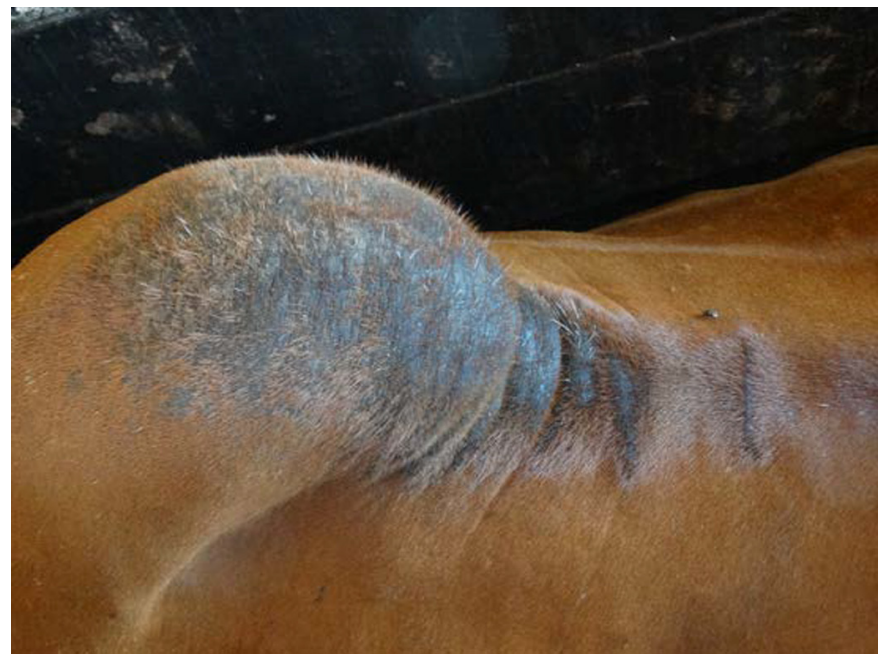

Fig.6. Bovino da raça Gir com otite causada por larvas de Rhabditis blumi. A alopecia na região do cupim foi causada pela fricção dos próprios chifres durante o desconforto e estresse do prurido da região auricular.

Também foi observado que alguns bovinos apresentavam alopecia na região da cabeça provocada pela fricção desta região nas cercas dos currais. Os bovinos também friccionavam a pele do cupim (Fig.6) com os próprios chifres, causando lesões alopécicas semelhantes às encontradas na cabeça. Essas lesões de pele eram causadas pelo desconforto e estresse ocasionados pelo prurido da região auricular, alterações que ainda não havia sido descrita por outros autores. Os raspados de pele das regiões alopécicas resultaram negativos.

Em quatro bovinos adultos com otite, foi observada sintomatologia nervosa, caracterizada por leve a moderada rotação e balançar da cabeça, apatia, flacidez dos lábios e ptose palpebral unilateral, alteração na mastigação e acúmulo de alimento na cavidade oral. De acordo com Msolla et al. (1993), Abdalla et al. (2008) e Campos et al. (2009), os sinais clínicos nervosos observados no presente estudo são característicos de uma otite interna já agravada e com comprometimento do sistema vestibular e do nervo facial, consequente de uma evolução clínica acima de seis meses.

Como principais diagnósticos diferenciais da otite causada pelas larvas de $R$. blumi podemos citar listeriose, otites por miíases, especialmente se agravadas por infecção bacteriana secundária. Estudo bacteriológico de otite causada por Raillietia spp. associou os gêneros Proteus e Pseudomonas com os processos inflamatórios crônicos na orelha dos bovinos (Leite et al. 1987). Em outro estudo, Duarte et al. (1999) sugeriram a participação de leveduras do gênero Malassezia na etiologia da otite parasitária bovina causada por nematódeos rabditiformes e ácaros do gênero Raillietia.

Os tratamentos realizados no $\mathrm{G} 2$ com $5 \mathrm{ml}$ de ivermectina a $1 \%$ nos pavilhões auriculares, e no G3 com as lavagens do CAE com o uso álcool e éter na proporção de 1:1 contendo sulfato de cobre a $2 \%$, surtiram pouco efeito na eliminação dos parasitas. Apenas 20\% (2/10) dos bovinos foram negativos em duas coletas com o uso da ivermectina. Resultados ineficientes com o uso desta droga na concen- 
tração de $0,5 \%$ foram também relatados por Verocai et al. (2009). Diante dos dados obtidos, a ineficiência desta droga no combate a estes parasitas possivelmente pode estar relacionada com a resistência destes ao produto usado, ou que seria necessário o uso da droga em concentrações mais elevadas.

No G3 a lavagem do CAE proporcionou apenas uma diminuição na carga parasitária e no cerúmen quando comparado com o início do tratamento. Este resultado foi diferente do obtido por Leite et al. (1994) que observaram $100 \%$ de eficiência. Contudo, Vieira et al. (2001) reproduziram o tratamento realizado por Leite et al. (1994) e também não conseguiram a mesma eficácia.

\section{CONCLUSÕES}

Baseado nas observações clínicas, morfológicas e moleculares pode-se relata-se otite por Rhabditis blumi em bovinos da raça Gir no Estado do Pará, procedentes de áreas onde essa parasitose tem sido diagnosticada.

Ressalta-se a presença de $R$. blumi no saco conjuntival de bovinos.

Os tratamentos realizados apresentaram baixa eficiência no controle da enfermidade.

A transferência de animais sem exame clínico prévio pelos serviços veterinários culminou na entrada dessa parasitose na região Norte do país.

\section{REFERÊNCIAS}

Abdalla M.S., Peixoto T.C., Alves P.A.M., França T.N. \& Brito M.F. 2008. Aspectos anátomo-patológicos da otite causada por Rhabditis sp. em bovinos no estado do Rio de janeiro, Brasil. Anais. Disponível em <http:// www.sovergs.com.br/conbravet2008/anais/cd/ resumos/ R0743-1. pdf> Acesso em 20 set. 2014.

Bossi P.V., Consoli E.A., Rosa J.M.O., Leite L.B., Leite R.C. \& Oliveira C.M.G. 2015. Molecular identification and phylogenetic analysis of Metarhabditis blumi (Nematoda: Rhabditida). Vet. Parasitol. Disponível em <http:// dx.doi.org/10.1016/j.vetpar.2015.06.014> Acesso em 10 nov. 2015.

Campos S.B.S., Serodio J.J., Brazil D.S., Silva T.V., Prado T.D., Mourav M.B.D. \& Silva. L.A.F. 2009. Evolução clínica, diagnóstico, tratamento e achados de necropsia da otite parasitária por Rhabditis sp. em touro da raça Gir - relato de caso. Ciênc. Anim. Bras. 10(Supl.I):677-683.

Dirksen G.H., Gründer D. \& Stöber M. 1993. Rosenberger, Exame Clínico dos Bovinos. 3 a ed. Guanabara Koogan, Rio de Janeiro, p.156-158.

Duarte E.R. \& Hamdan J.S. 2004. Otitis in cattle: an aetiological review. J. Vet. Medical. 51:1-7.

Duarte E.R., Melo M.M. \& Hamdan J.S. 2001. Epidemiological aspects of bovine parasitic otitis caused by Rhabditis spp. and/or Raillietia spp. in the state of Minas Gerais, Brazil. Vet. Parasitol. 101:45-52.

Duarte E.R., Melo M.M., Hahn R.C. \& Hamdan J.S. 1999. Prevalence of Malassezia spp. in the ears of asymptomatic cattle and cattle with otitis in Brazil. Med. Mycol. 37:159-162.

Leite R.C. 1989. Railietiose bovina. Tese de Doutorado em Ciências, Medicina Veterinária - Parasitologia Veterinária, Universidade Federal Rural do Rio de Janeiro, Seropédica, RJ.

Leite P.V. \& Leite R.C. 2010. Otite parasitária em bovinos da raça Gir. Revta Interural 4(33):52.

Leite R.C., Nunes V.A., Coelho A.M.B. \& Chaquiloff M.A.G. 1987. Patologia da infecção do ouvido de bovinos por Raillietia auris (Leidy, 1872) Trouessart, 1902 (Acari, Mesostigmata). II. Achados bacteriológicos. Arq. Bras. Med. Vet. Zootec. 39:325-332.

Leite R.C., Nunes V.A., Nunes I.J., Costa A.L., Faccini J.L.H. \& Lopes C.W.G. 1993. Otite parasitária por nematóides rhabditiformes: aspectos epidemiológicos e clínicos. Revta Bras. Med. Vet. 15(2):49-51.

Leite R.C., Leite R.C. \& Faccini L.H. 1994. Diagnóstico e tratamento da otite parasitária por nematódeos rhabditiformes em bovinos. Revta Bras. Parasitol. Vet. 3:69-70.

Leite P.V.B., Leite L.B., Cunha A.P., Silva M.X., Bello A.C.P.P., Domingues L.N., Leite Jr A. \& Leite R.C. 2013. Clinical aspects and dynamics of auricular parasitosis in Gir cattle. Pesq. Vet. Bras. 33(3):319-325.

Martins Jr W. 1985. Rhabditis (Rhabditis) freitasi sp. n. e Rhabditis (Rhabditis) costai sp. n. (Nematoda-Rhabditidae) isolados de otite bovina. Mem. Inst. Oswaldo Cruz 80:11-16.

Mráèek Z., Nguyen K.B., Tailler P., Boamare N. \& Chen S. 2006. Steinernema sichuanense n. sp. (Rhabditida, Steinernematidae) a new species of entomopathogenic nematode from the province of Sichuan, East Tibetan Mts., China. J. Invertebr. Pathol. 93:157-169.

Msolla P., Matuf E.P.M. \& Monrad J. 1986. Epidemiology of Bovine Parasitic Otitis. Trop. Anim. Health Prod. 18:51-52.

Msolla P., Semuguruka W.D., Kasuku A.A. \& Shoo M.K. 1993. Clinical observations on bovine parasitic otitis in Tanzania. Trop. Anim. Health Prod. 25:15-18.

Pitombo L.H. 2008. Vermes que causam doloridas otites. Revista ABCZ. Disponível em <http://girbrasilartigos.blogspot.com.br/2008/01/vermes-causam-doloridas-otites.html> Acesso em 17 ago. 2014.

Rezende R.B. 2010. Otite parasitária causada por Rhabditis spp. em bovinos. Monografia de Especialização em Medicina Veterinária, Faculdade de Medicina Veterinária, Universidade Federal de Goiás, Jatobá. 48p. Disponível em <https://veterinaria.jatai.ufg.br/up/178/o/Rafael\%20 Batista\%20Rezende.pdf> Acessado em 15 fev. 2014.

Sambrook J., Fritsch E.F. \& Maniatis T. 1989. Molecular Cloning: a laboratory manual. 2nd ed. Cold Spring Harbor Press, Cold Spring Harbor, NY.

Tamura K., Peterson D., Peterson N., Stecher G., Nei M. \& Kumar S. 2011. MEGA 5: Molecular Evolutionary Genetics Analysis using Maximum Likelihood, Evolutionary Distance, and Maximum Parsimony Methods. Mol. Biol. Evol. 28(10):2731-2739.

Tomazini M.D., Aguillera M.M., Rodrigues R.C.D., Bessi R., Harakava R. \& Oliveira C.M.G. 2013. Biometric and molecular analysis of Brazilian isolate of Rhabditis rainai (Nematoda: Rhabditidae). Nematol. Bras. 37(1/2):1-8.

Verocai G.G., Fernandes J.I., Correia T.R., Melo R.M.P.S., Alves P.A.M. \& Scott F.B. 2007. Otite parasitária bovina por nematoides rhabditiformes em vacas Gir no Estado do Rio de Janeiro, Brasil. Revta Bras. Parasitol. Vet. 16(2):105-107.

Verocai G.G., Fernandes J.I., Correia T.R., Melo R.M.P.S., Alves P.A.M., Scott F.B. \& Grisi L. 2009. Inefficacy of albendazole sulphoxide and ivermectin for the treatment of bovine parasitic otitis caused by rhabditiform nematodes. Pesq. Vet. Bras. 29(11):910-912.

Vieira M.C.M. 1998. Otites clínicas por Rhabditis sp. em bovinos da raça Gir no Estado de Goiás: estudo da prevalência, alguns aspectos da biologia dos parasitos e tratamento. Dissertação de Mestrado em Sanidade Animal, Escola de Veterinária, Universidade Federal de Goiás, Goiânia.

Vieira M.C.M., Silva L.A.F., Araújo J.L.B., Andrade M.A., Fioravanti M.C.S. \& Silva E.V. 2001. Otites parasitárias por nematódeos rhabditiformes em bovinos: avaliação de tratamentos. Ciênc. Anim. Bras. 2:51-55.

Vieira M.C.M., Silva L.A.F., Borges N.C., Araújo J.L.B., Santin A.P.I. \& Silva E.V. 1998. Estudo da prevalência de otites clínicas por Rhabditis sp. em bovinos da raça Gir no Estado de Goiás. Anais Esc. Agron. Vet., Goiânia, 28(2):19-29. 